\title{
Land Regularization and Community Development Nexus in Cities of Sub Saharan Africa: A Critical Review with Urban Growth and Development Perspectives
}

\author{
Edmund Zakayo ${ }^{1}$, Emmanuel Patroba Mhache², Magigi Wakuru ${ }^{3}$ \\ ${ }^{1}$ The Open University of Tanzania, Department of Community Economic Development \\ ${ }^{2}$ The Open University of Tanzania, Department of Geography \\ ${ }^{3}$ Ministry of Agricultural, Tanzania Cooperative Development Commission,
}

\begin{abstract}
Land regularization is an emerging urban planning tool which is directly linked to community development, particularly when one want to acquire title deed in unplanned settlements in cities of SubSaharan Africa. This paper contributes knowledge base critically with a view on land regularization and community development reviews in cities growth and development processes perspectives. Different urban planning approaches and modes have been discussed to provide a base for critical analysis and understanding in the context of land regularization and community development nexus, interlinkages and their impacts in Sub-Saharan Cities for learning and replications.
\end{abstract}

Keywords: Land Regularization, Community

\subsection{Introduction}

Land regularization and community development are interlinked terms, particularly when one aim at improving living standards of residents in unplanned and un-serviced settlements. In this context, land regularization is defined as an urban planning process and a tool in formalization of informal settlements through upgrading and formal title deed acquisition. The process of land regularization aims at bringing the informal and unauthorized settlements within the official, legal and administrative systems of land management through land use planning, land registration, surveying, service improvement and finally granting right of occupancy (title deeds) to residents in their local areas (Magigi and Majani, 2006; Shaibu, 2010; Yonder et al. 2011; Magigi, 2013). The process among others increases urban social inclusion through creating employment, social safety nets, housing provision, and spreading the benefits of economic development between and within cities, which enhances community development (Habitat, 2016). Discussing models and approaches for urban growth and development in urban planning context and movement is closely linked to
Development, Title Deeds, Urban Growth community development. Particularly when residents, government and other urban development stakeholders focus on improving livelihood of the residents in both developed and developing countries cities.

In developing countries particularly in SubSaharan Africa, urbanization is a common feature, whereby, cities found characterized by low income majority who are living in informal settlements and lack or with inadequate infrastructure services (Montgomery, 2007; Linard et al., 2013). Residents in these settlements live in congested houses and densely populated, limited infrastructure such as water, electricity, roads, and waste collection points leading to augmented poverty (URT, 2012; IBD, 2014). These characteristics results of donor initiatives to support in addressing the same. For example, since 1960 the United Nations have supported developing countries in terms of grants and aid provision to address urbanization challenges and strengthening community development initiatives in settlement upgrading through slum clearance in the cities of Sub-Sahara Africa including Tanzania. Other initiatives include presence of national and international conventions aimed at 
discussing urban challenges and putting jointly strategies for improving urban residents, safety and growth such as the Ramsar Convention of 1977, Bruntland Convention of 1987 and Rio de Janeiro Earth Summit of 1992. Likely, Habitat III summit on efforts to implement the 2030 agenda for sustainable development, gives a prominent role towards ensuring cities are inclusive, safe, resilient and sustainable for community development. Thus, the city growth and development process, approaches, country development' initiatives and international convectional are closely linked to community development and thus, reducing poverty and creating a healthy city for living.

\subsection{Study Approach And Methods}

The central approach of this study used is a critical review of literature. It involves pointing out the study variables. These variables include land regularization, community development, title deeds and urban growth based on the study context and focus. Also, various scholars' works related to the study variables were reviewed, synthesized and compiled scientifically. This was done by analyzing the results reported by studies, and drawing issues on land regularization and community development in cities of Sub Saharan Africa. However, findings from these studies are critically analyzed, discussed and compared to theoretical, practical base and addressing the implications resulting from urban planning practices.

\subsection{Findings And Discussions \\ 3.1 City Growth Trend and Models \\ Trend of urban growth}

Urban growth has attracted many scholars' attention in their debate in both developing and developed countries. It is seen to be an important component of the urban planning process and practices towards enhancing local community development. Urban growth refers to the increase of population, in which such increase lead to intensive use of land, including building houses for living for residents and infrastructures to support such growth (Oyeleye 2013). In different countries, in fact urban growth mostly is influenced by the increase in population, resulting from the natural increase in population and migration to urban areas. It involves also an expansion of the economic base and industrial development. Since industries are established in the countryside, it encourages construction of housing and other social services for people working in industries and business centers (Bhatta, 2010; Opoko and Oluwatayo, 2014; Agwanda and Amani, 2014; Tumbe, 2016). In developed countries, during the $19^{\text {th }}$ and $20^{\text {th }}$ centuries, urban growth was a result of industrial development. New job opportunities from industrialization in urban areas inspired the majority of people to move from villages to cities to work in emerging factories (Bhatta, 2010).

However, in Africa, it is different compared to developed countries. Urban growth since 1960 resulted from the use of technologies and amalgamation institutions introduced from colonialism and trade, which reduce the mortality rate and increased access to food, contributed by improvement of productivity and international aid. In sub-Saharan Africa, Archaeological evidence and oral histories prove the existence of settlements in urban areas for over 2000 years. However, in comparison to other countries of the world these settlements remained small and very few (Fox, 2011).

In Tanzania, from 1990 to 2010 cities like Dar es Salaam the annual growth rate was $4.67 \%$ and in Africa was ranked the third fastest growing urban area. This growth resulted from economic growth with connection to employment, especially after independence. Also, in Tanzania urban growth is not uniform to all cities, but it is more common in Dar es Salaam due to uniqueness found in the city compared to other regions. Availability of employment opportunities from public and private organizations, business centers, and social and economic services like hospitals, universities, diplomatic missions, transportation centers and among others attract many people to move from other regions (Hill and Lindner, 2010; Mkalawa and Haixiao, 2014).

Urban growth is argued by different scholars to have both positive and negative impacts in different countries. However, negative impacts seem to be more common in developing countries, while positive impacts most common in developed countries. Bhatta (2010) argues that negative impacts are mostly pointed out since this urban growth is ungraceful and thus negative impacts dominate the positive sides. Positive implication enable availability of social services like transportation, education and health care to people. 
In the countries of South Asia such as Bangkok, Jakarta, Manila, and Taipei urban growth have exceeded the capacity of cities to provide social services such as water, sewer, electricity, transportation, health care, and education to people. Yet every day cities continue to attract many people from villages who increase the population and expand informal and unplanned settlements, worsening problems of urban congestion and hindering government' efforts in the provision of basic services (Cohen, 2006).

In Nigeria, government has failed to cope with the urban growth challenges. Subsequently, social services are hardly provided as urban growth occurs unevenly with negative impacts to the living standards of the people in urban areas (Opoko and Oluwatayo, 2014). In Tanzania, urban growth, does not comply with city planning standards, resulting in growing informal and unserviced settlements (Mkalawa and Haixiao, 2014).

Developing countries have not benefited much from urban growth compared to developed countries. Urban growth has benefits, but since in developing countries negative impacts dominate the positive ones, it is ungraceful. This show that developing countries fails to cope with effects brought by the increase in population (Opoko and Oluwatayo, 2014). This situation is common in most countries in Africa, including Tanzania (Mkalawa and Haixiao, 2014). Cohen (2006); Opoko and Oluwatayo (2014); Mkalawa and Haixiao (2014) argues that many developing countries have failed to cope with urban growth effects because they have master plans, guidelines, policies and regulations guiding land development and for the future direction of urban growth, but the problem is failure to effect the implementation accordingly. Among of the reason documented is the local government being the main implementer while they have inadequate resources. In developed countries government plans new settlements and attract residents who migrate from villages to come and live in those settlements located in urban areas. This is different in developing countries, whereby people come from villages and build house in unplanned areas, as a result, informal settlements with limited social services grow, and eventually it becomes difficult for government to provide services. As a result, when local governments plan to formalize these settlements upgrading adopted which is difficult attempts to undertake due to congested houses in one area and heavily resources are required for its implementation.

\section{Models of Urban Growth and rational in African cities}

Urban growth models have been developed by scholars to depict urban expansion phenomenon and its impact to the city environment, and residents' livelihood sustainability. This can be used in the urban policy formulation and urban development, analysis and exchange ( $\mathrm{Li}$ and Gong, 2016). One of the models commonly discussed is the Concentric Zone. This model was developed by Earnest Burgess in the 1920s. Abrahamson (2013) argues that " ...the concentric zone model depicts the use of urban land as a set of concentric rings with each ring devoted to a different land use" (see Figure 1). Also, according to Carter and Polevychok (2006) the model "...was fundamental for establishing neighborhood change as an inevitable, natural result of competition for space". 


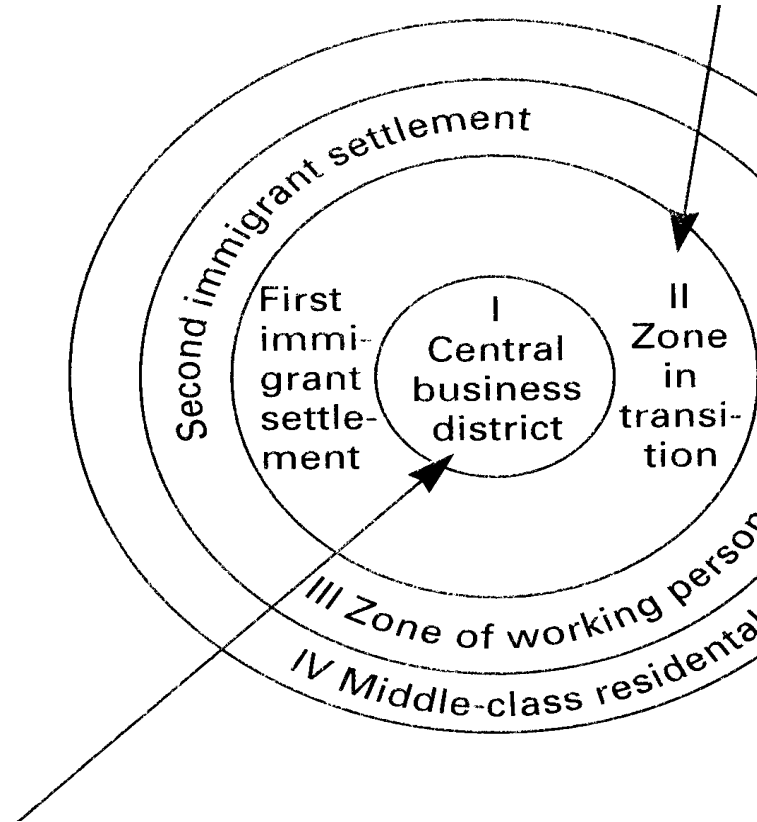

Source: Meyer (2000)

\section{Figure 1: Concentric growth zone}

Major roads of transportation originated from the city's core, leading the Central Business District (CBD) the most reachable in the city. ....."Burgess identified five rings of land use that would form around the CBD connections roads. These rings are originally defined as the (1) central business district, (2) zone of transition, (3) zone of independent workers' homes, (4) zone of better residences and (5) zone of commuters" (Meyer, 2000).

According to Meyer (2000) the central feature of the model is the positive relationship between the social and economic status of people with distance from the central business district, rich people were found living very far from the central city. "....Burgess described the changing spatial patterns of residential areas as a process of "invasion" and "succession"'.

As the city grew and advanced over time, the central business district would "....exert pressure on the zone immediately surrounding it (the zone of transition)".

Outward expansion of the central business district would conquer close residential neighborhoods triggering them to expand outward. The process continued with each successive neighborhood moving more from the central business district. The immigrants and households with low social

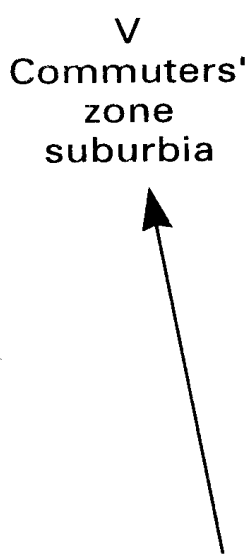

grew

and the central business district expanded outward, lower status people moved to adjacent neighborhoods, and more rich people moved further from the central business district (Fyfield, 2003; Carter and Polevychok, 2006).

Urban expansion involving the spreading of houses and shopping centers in urban is not uniform in all cities of the world, as such the application of the Concentric Zone Model in current cities in the world is limited. Various scholars question the applicability of the Ernest Burgess's Model of Urban Growth in the current cities. Etienne (2008) claims that "....the model emphasized on the economic characteristics of areas, ignoring other important factors, such as race and ethnicity, which may underlie urban land use change". Also, Liu (2014) supports that "....because of advancement in transportation and information technology, and transformations in the global economy, cities are no longer organized with clear zones". Luque (2015) argues that in the Paris metropolitan area the affluent residents live in the inner-city, the development of the city has not exerted pressure for them to move. Bailey and Minton (2016) support that also in London, and other four largest cities of Scotland richer people have been living in inner-city and poorer people are being pushed out. The rich population lived in the central business district between the year 2004 to 2016 has remained the same or increased, while the proportional poor people has been declining. 
These arguments shows the limited applicability of the model in both developed and developing countries' cities. In Tanzania and other developing countries, its community abscond that at the CBD land area/plots are sold at a higher price. As one moves to the peripherals from the center the price for land and housing rent decrease. This situation makes poor citizens' failure to afford living in inner-city, and thus living very far from central urban centers. This show cities meant for people who can develop land accordingly, and not for the poor. The poor use to enjoy the services provided by the council and social exclusion and inclusion exist. The model applicability is difficult, especially minimum resources we have in developing countries.

\subsection{Approaches to urban planning}

Various scholars have discussed various urban planning approaches, including participatory eplanning approach, top-down approach, mixed top-down and bottom-up approach, bottom-up approach and land regularizations. Magigi (2010) defines urban planning approaches that are "processes involving the organization of various development partners who either benefit from or are affected by the spatial and land use dimensions of urban development, and who guide and manage the process. Also, coming together to determine the fate of the planning practices, since land use planning will involve informed information for decision making. The aim here is to ensure proper coordination of planning practices which increases the city's competitive advantage, productivity and safety".

\section{Participatory e-Planning Approach}

Participatory e-Planning approach involve the use of Information and Communications Technologies (ICTs) in urban planning to encourage citizen participation in the design and use of media and other ICTs tools to provide and share information related to planning (Horelli et al., 2013). SaadSulonen and Horelli (2010) highlights that participatory e-planning comprises different types of participation that take place in urban planning, as well as in the design of digital technology. The different types of participation can occur simultaneously in different combinations and they can affect one another. According to SaadSulonen and Horelli (2010) participatory eplanning can put urban planning in community development and governance, as it involves channels to collect and disseminate information using both traditional and ICTs tools.

Aikins (2010) argues that the participation of citizen in urban planning and development agenda is very important to enable them own decisions and have a sense of ownership of the development process. The development of Geographic Information Systems (GIS) and Planning Support Systems (PSS) has enabled planning organizations and various actors to adopt and use participatory e-planning in making development decisions with the inclusion of various development actors. According to Wallin and Horelli (2012) the traditional types of participation like neighborhood meetings have been complimented by the use of digital tools, that provide opportunities for people not only living in a place, but even those who want to be involved in urban planning and live other places. They can share their views, comment and makes decisions from various locations supported by digital tools such as mobile phone, computers and urban screens.

Steiniger et al., (2016) have pointed out that participation of the citizen should be an important part if the needs of local community needs to be addressed. A complementary form of a community participation in public planning meetings is to enable community involvement through digital tools, even those who cannot reach due to different reasons. Also, participatory ePlanning informs citizens and interested groups on ongoing development projects and get opportunities to discuss them online.

\section{Top-down Approach}

Top-down approach is also called government controlled urban planning approach. In this approach the community is not involved in decision making, all decisions are made by the government, corporations or the planner. In topdown approach the government carry out the urban planning process, own the authority to make the final decisions, and the citizens do not involve from setting goals and execution (Zhang, 2015). Pissourios (2014) noted that top-down approach is effective for some of planning, for example, regional and strategic urban planning, where other approaches cannot work, since it needs professional, knowledge and skills. Liedl (2011) pointed out that the approach favors the decisionmakers as important stakeholders in the implementation process and consider 
administrative staff that conducts the legal act as important. A real example is the use of master planning where mainly use zoning regulations for many decades. This had no flexibility and thus need to change to become obligatory in urban planning practices.

\section{Bottom-up Approach}

Roy and Ganguly (2009) highlights that “...the bottom up approach in planning may be traced back in 1960's and started getting popularity among planners. The outcome like 'existing issues', 'priority projects' have been better from the bottom up approach. However, more proactive planning objective has not fulfilled from a bottom up approach". According to Pissourios (2014) the important requirement for adoption of bottom-up approach is the existence of "bottom level" which is the community that have needs, priorities, and prospects, also willing to participate in planning to meet their needs and demands. On the other hand, in some occasions there is no 'bottom level', like the new settlements or large city plan expansion. On such occasions, there is not yet a community that the bottom-up approach cannot be implemented as a result the top-down approach can be adopted. Liedl (2011) emphasize that bottom-up approach is effectively where top down fails to succeed.

\section{Mixed top-down and bottom-up Approach}

Mixed top-down and bottom-up Approach is also referred as joint decision making urban planning approach. In this approach, urban planning decisions are done by both public and government, there should be agreement on the design, goals setting, implementation and also monitoring and evaluation (Zhang, 2015). The approach is considered important as it fills gaps that can be experienced in both top-down and bottom-up Approach (Crescenzi and RodríguezPose, 2011 cited in Kägu, 2015).

\section{Land regularization approach}

Land regularization, as a participatory urban planning approach, enables urban residents in informal settlements to own land formally and enabling them to acquire title deeds. The process entails, among others the provision of social and physical infrastructures, taping untapped financial resources through community contributions, whereby; all these require or are influenced by local governance. The land regularization process aims to ensure social services, business development and housing improvement, which are all indicators of local community development towards strengthening their lives (Magigi, 2010; Magigi, 2013).

Land regularization results from common problems faced by residents in the community. These include increased land conflicts, fear of eviction by the government, saturated houses and densely populated, shortage of surveyed land and inadequate infrastructure, land speculations, and lack of capital for the majority of urban residents leading to poverty. These commonly felt problems results from uncontrolled urbanization and motivate the community to come together and collectively work to address such problems (Kessy, 2005; URT, 2012; IBD, 2014). However, most of informal settlements in Africa, especially sub-Saharan have not been regularized due to limited financial resources, despite the redness of community members to contribute resources.

\section{Capacity Building of the Local Government Authorities Approach}

The approach is commonly used in various countries in Africa, including Tanzania and Zimbabwe. In Tanzania it has been used to implement the Property and Business Formalization Program; popularly known in Swahili acronym as MKURABITA. This approach was initiated to make sure the formalization process is owned at local government authorities and later implementation directly touches local community at local level (CLKnet, 2013). To summarize Vincent and Stephen (2015) stated that the approach strengthens the technical capacity of local government authorities in various areas including planning; budgeting; implementation; and management. Likewise, the approach aims to reduce government funding of services in urban areas and allowing service charges to be levied by local authorities and the private sector, such as private companies, Non-governmental organizations and other community based organizations to provide services.

Urban planning approaches have been discussed by several authors differently in its applicability and effectively to community development. Participatory e-Planning approach is good, it collect and disseminate information, and 
providing opportunities for people to discuss development process online with the support of Information and Communications Technologies (ICTs) tools. Thus, Steiniger et al., (2016) note the biggest user group of participatory e-Planning is community members through digital tools. The application of this approach is difficult in areas where there is limited internet access like Africa. Also, in developing countries the majority of local communities have no smart phones to support participatory e-Planning, likewise, the accessibility of the internet, illiteracy and limited power are among of factors hindering its applicability. In some developing countries attending meeting physically is still limited for the majority of the people, which needs to be promoted so that communities can meet physically and discuss their own development and eventually makes decisions.

In respect to top-down approach, Magigi (2013) emphasize that the top-down planning approach was common in government-led urban planning process like master plan in various countries such as Zimbabwe, Botswana, Zambia, Tanzania, Namibia and other Sub-Saharan African countries. However, this approach is not common in these countries. Pissourios (2014) contends that topdown approach is effective for regional and strategic urban planning, and thus it is important to be used on such occasions.

In addition, bottom-up approach appear as a response to enhance community participation in development processes. The approach helps people to own development process and thus able to contribute resources for better achievement of desired goals. CLKnet (2013) documents bottomup approach ensure local communities own the process from setting goals to implementation of development processes. Liedl (2011) and (Kägu, 2015) emphasize that in planning both top-down and bottom-up urban planning approaches are used to fill gaps that can be experienced in both top-down and bottom-up Approach. In developing countries, both approaches have been effective and it has enabled local communities to share their resources in the development process and integrate their needs in the development projects. Pissourios (2014) emphasizes that using the topdown and bottom-up approach for community development is better, as there some occasions where one approach cannot fit than the other is used. Thus, in urban planning, in some step one approach can be used, and in another step the other approach is used.

Also, considering the increase of informal settlements due to urban growth, land regularization is important as discussed by various scholars such as Kessy (2005); URT (2012); IBD (2014). Various challenges emanating from ungraceful urban growth, motivate local communities in the settlements to come together and contribute resources for land regularization. But, since these settlements are upgraded the government and community expectations from land regularization are not realized. De Soto (200) and Magigi (2013) identifies community and government expectations from land regularization including provision of social services and acquiring title deeds. In reality, these expectations have not been archived effectively. This shows the challenges in settlements upgrading, where land regularization has been implemented in place already community members have constructed houses in poor plan and thus difficult to provide infrastructures like roads, unless some of the households are shifted which is difficult. Also, other services like schools, health centers and children play ground because are difficult to construct since there is no space for such infrastructures.

\subsection{Approaches for community development}

The community development literature has identified three major approaches for community development, including technical assistance, selfhelp approach and conflict approach;

\section{Technical assistance}

Technical assistance is a community development approach that depend on mostly on experts to assist the local community in any or all phases which include planning, implementation and evaluation. A good example of technical assistance is when community members with their leaders they need to prioritize a most common problem faced in the community, then an expert or external person can be involved in the process to guide them to prioritize their needs. It allows communities to access outside expertise in areas that need expertise like project writing for funding. The approach help communities to define their problems and community members strengthened and getting expert know-how to solve their problems (Burkhart-Kriesel, 2005; 
Robinson and Green, 2010; Gallardo, 2015). In addition, Arefi (2010) and Gallardo (2015) highlights that technical assistance approach is transferred through top-down policies, as such, it helps in two main ways; one is transferring financial, organizational and political assistance from external sources to specific communities. The second way is enhancing a sense of ownership among communities and empowering marginalized communities.

\section{Self-help Approach}

Self-help is demonstrated through activities that involve the process of setting vision and goals. The approach is generally regarded as capacity building and not depending on external supports. Possibly the best self-help approach of community development is asset-based, which is the process of involving community members to identify assets i.e. individual, organizational and institutional resources and capacity and not needs. These assets can be used effectively to solve community problems (Burkhart-Kriesel, 2005; Gallardo, 2015). Burkhart-Kriesel (2005) and Arefi (2010) emphasizes that the goal of the selfhelp approach is community empowerment to solve problems in the long run. Self-help is centered on ability to self-organize using talents, skills, experience of local communities in solving problems they face, while technical assistance involves support from outside.

\section{Conflict Approach}

The last community development approach is conflict. Although the majority of community members avoids conflicts, but conflicts can stimulate community development as it can redistribute power and responsibilities in the community. Gallardo (2015) argues that “....in a community development context, conflict should be seen as a process, not an outcome". Arefi (2010) explain that conflict approach has two central objectives providing rooms for conflict resolution and encouraging consensus on shared interests and goals. Gallardo (2015) points source of conflicts, including difference in values and interests, poor communication and among others. Benefits of conflicts that a community may experience include people being forced to problems and take action, strengthens social norms and networks, and establish better long term relationship. However, conflicts to stimulate community development it must "satisfy substantive (win-win), procedural (fair process), and psychological (heard and respected) needs"

Technical assistance is important to community development. Gallardo (2015) argues that the technical assistance approach is important when government provides services and work with the community. This show that in some of the community development projects, community members on their own cannot implement and meet the desired goals. In developing countries where governments implement projects using most of the resources from the community themselves like construction of schools, this approach is commonly used.

In addition, self-help approach involves the community members organizing themselves and solving their own problems without external support. This approach is effectively used when the activity or project does not require expertise that they don't have. Gallardo (2015) argues the change must have a change agent or a person leading change, then if such person is not effective, then the expected change cannot be realized. Therefore, this approach is applicable in situations where the community themselves have a strong change agent who can lead change, and in case no such person the technical assistance can be used to meet the desired change (BurkhartKriesel, 2005; and Gallardo, 2015).

In respect to conflict, Gallardo (2015) argues that conflicts stimulates community development. But, in developing countries where there have been conflicts like Congo, Sudan and Burundi developments have been late. Also, in nomadic and agricultural communities, where conflicts between pastoralists and farmers exists, it has been difficult to bring development in those communities, causing deaths and migration of people. Arefi (2010) provide precaution that conflicts bring community development if are handled properly. Poor resolution in the community makes conflicts to expand and cause negative effects. As such, Gallardo (2015) highlights that conflict manager is crucial in the process of ensuring local community development.

\subsection{Lessons Learned}

Urban growth in most of developing countries results from migration of people from rural to 
urban centers, for easy access to social services as well as economic opportunities. This is different in developed countries which industry development is the major determinant for migration. Urban growth resulted from migration in developing countries, it has become ungraceful due to poor plans for coping with such growth. The communities migrating to urban areas are accommodated in squatters which are characterized by poor access to social services. This shows the need of developing countries governments to ensure availability of social services in rural areas to control migration, stimulate and create conducive environment for industries development so that can be a major force for migration.

The concentric growth model in the context of developing countries its applicability is limited. This is because poor people cannot afford living expenses of the inner-city. Most of the developing countries, governments have no plan for people who move from inner-city to outside it is their own living strategy, whereby most of them fail to cope with urban life. When people move out they establish new unplanned settlements with limited access to social services. After years the government go to upgrade these settlements, which raise questions to why the area was not planned before being occupied by people. As such, it is important for governments in developing countries to ensure all areas nearby urban centers are planned before being occupied by people. The need of having land rangers to guide urban development is rational in urban planning practices.

Reflecting Earnest Burgess Model in developing countries planning mostly lags behind settlements development. The model can be easily established where land is virgin, a situation which is difficult to be noticed in urban areas in Africa. Thus, its applicability in developing countries cities development, becomes difficult. Likely connectivity and expensiveness are common constraints feature caused by economic and budgetary problems. Reflecting Abrahamson (2013) argumentations on the model, is good as it shows the potential of having planned land use, development pattern and zoning regulation enforcement. In this context clustering of the group may occur, which is not a bad case in city growth and development processes. Likely, connectivity is easily achieved.
Many urban areas around the CBD of African cities have been planned and developed, so it is expensive to construct ring roads as it will involve demolishing, compensation and dramatic shift of urban residents a situation which is more expensive under budgetary constraints in African countries, Tanzania inclusive.

Urban planning approaches, especially top down and bottom up approaches have been commonly used in community development processes. But its applications have not been verified in development processes. Some of development practitioners who have been leading bottom up approach have been ineffective to some of the processes. Such processes include awareness creation to all actors on what is going on, its importance to their development, their roles, and involvement of key actors in the process. These processes are important as creates a sense of ownership and enable communities to contribute resources for development initiatives. Lack of ownership of various actors has led to unsuccessful implementation of development activities like land regularisation. When local communities have limited awareness their implementation is normally poor due to lack of need for achievement. This shows the need of development practitioners to provide awareness creation to communities so that can have ownership and know their role in the process.

Land regularization and community development are interlinked. Land regularization aims at ensuring access to social services such as roads, waste deposits points, health, education, open space and among others, and also right of occupancy. Access to social services and right of occupancy are important determinant and indicator for community development However, land regularization to bring community development, community organizing and mobilization are important, for local communities to own the process and participate effectively. Since, the process is owned by local community themselves and coordinated by government, the great role of local or neighborhood leaders has been ignored and not considered important. Though, these leaders live with community members, and thus know their behaviour better than government officials. As such, after the completion of the land regularization, leaders does not mobilize local communities to construct roads 
planned, apply for title deeds, find permit for home improvements and proper waste disposal. Hence, community development desired by land regularization becomes unrealized, hence poverty persists in developing countries where informal dwelling is rampant.

\subsection{Conclusion Remarks}

After a critical review it has been found that there are closely interconnections between land regularization and community development in cities. The nexus is determined by how a country planned for implementation of land regularization and how they are important stakeholders, including the local community, local government, central government, civil societies and others participating in urban planning and its implementation, and enforcing output to cope with urban growth. Active participation of stakeholders, especially local communities in the land regularization process enable communities to own the process, which enable them to experience benefits from the process like access to services such as road network and acquiring title deeds, and eventually strengthening community development. Therefore, there is a need for government and civil societies to make sure local communities involve and participate from initiation of settlement upgrading to development control in the community. In addition, in respect to urban growth the review shows developing countries experience negative impacts while developed countries experience positive impacts due to the implementation of good policies already established. This show the need of developing countries to set and enforce urban growth policies and regulations for urbanization control in cities of emerging economy countries like Tanzania and elsewhere.

\section{References}

1. Abrahamson, M. (2013). Urban Sociology. Cambridge University Press, United Kingdom.

2. Agwanda, A., \& Amani, H. (2014).

Population growth, structure and momentum in Tanzania. THDR 2014:

Background Paper No. 7 ESRF Discussion Paper, 61.

3. Aikins, S. K. (2010). Participatory EPlanning: Bridging Theory and Practice through. Politics, Democracy and EGovernment: Participation and Service
Delivery: Participation and Service Delivery, 131.

4. Arefi, M. (2010). Asset-based approaches to community development. UNHABITAT.

5. Bailey, N. and Minton, J. (2016). Cities will just be playgrounds for rich if poor keep being pushed to suburbs. [http://theconversation.com/cities-willjust-be-playgrounds-for-rich-if-poor-keepbeing-pushed-to-suburbs-64708] Site Visited on 14/10/2017.

6. Bhatta, B. (2010). Causes and consequences of urban growth and sprawl. In Analysis of Urban Growth and Sprawl from Remote Sensing Data. Springer Berlin Heidelberg.

7. Burkhart-Kriesel, C. A. (2005). Three Potentially Effective Approaches to Community Change. Cornhusker Economics, 215.

8. Carter, T., \& Polevychok, C. (2006). Understanding disinvestment and decline. Winnipeg: Department of Geography, University of Winnipeg. 45pp.

9. CLKnet (2013). The Role of Local Government Authorities in the Process of Formalizing Properties and Businesses in Tanzania.

10. Cohen, B. (2006). Urbanization in developing countries: Current trends, future projections, and key challenges for sustainability. Technology in society, 28(1), 63-80.

11. De Soto, H. (2000). The mystery of capital: Why Capitalism Triumphs in the West and Fails Everywhere Else: Basic Books Publishers: New York.

12. Etienne, F. (2008). Urban Growth and Segregation in the Roanoke, Virginia, Metropolis: The Effects of Low-Density Development on Low-Income Populations and Racial Minorities. Dissertation submitted as Award of Doctorate Degree at Virginia Commonwealth University, U.S.A.

13. Fox, S. (2011). Understanding the origins and pace of Africa's urban transition. Crisis States Research Centre Working Paper (Series 2) No. 98.

14. Fyfield, P.H (2003). Transportation and Land Use Patterns: Monitoring Urban Change Using Aerial Photography, Portland, Oregon 1925-1945. Thesis for 
Award of MA Degree at Portland State University, United States of America. $131 \mathrm{pp}$.

15. Gallardo, R. (2015). Community Economic Development: Approaches. Mississippi State University, United States.

16. Habitat, U. N. (2016). Urbanization and development: emerging futures; world cities report 2016. Nairobi, UN Habitat View Article Google Scholar.

17. Hill, A., \& Lindner, C. (2010). Land-use modelling to support strategic urban planning-the case of Dar es Salaam, Tanzania. In 45th ISOCARP Congress (pp. 1-12).

18. Horelli, L., Jarenko, K., Kuoppa, J., SaadSulonen, J., \& Wallin, S. (2013). New Approaches to Urban Planning-Insights from Participatory Communities. Aalto University.

19. IDB (2014). Comparative Evaluation: Land Regularization and Administration Projects. Office of Evaluation and Oversight, Washington, D.C, USA.

20. Kägu, A. (2015). Top-Down Meets Bottom-Up: Planning Futures in VäikeÕismäe in Tallinn. A Dissertation Submitted for Award of Doctoral, at Estonian University, Estonia.

21. Kessy, J. D. (2005). Land regularisation through participatory approach in Tanzania: the case of Ubungo Darajani-Dar es Salaam. A dissertation submitted for Award of Doctoral degree at Southern New Hampshire University, United States.

22. Li, X., \& Gong, P. (2016). Urban growth models: progress and perspective. Science Bulletin, 61(21), 1637-1650.

23. Liedl, C. (2011). Top-down vs. Bottom-up does a top-down approach bear more advantages than a bottom-up approach within the implementation process of housing security projects? A Thesis Submitted for Award of Bachelor Degree at University of Twente, Netherlands.

24. Linard, C., Tatem, A. J., \& Gilbert, M. (2013). Modelling spatial patterns of urban growth in Africa. Applied Geography, 44, 23-32.

25. Liu, Z. (2014). Applying a SpatioTemporal Approach to the Study of Urban Social Landscapes in Tianjin, China.
Dissertation submitted as Award of Doctorate Degree at University of Ottawa, Canada.

26. Luque, J. (2015). Urban Land Economics. Springer, United States of America.

27. Magigi, W. and Majani, B. (2006). Community involvement in land regularization for informal settlements in Tanzania: A strategy for enhancing security of tenure in residential neighborhoods. Habitat International. 30 (2006): 1066-1081

28. Magigi, W. (2010). Understanding urban planning approaches in Tanzania: A historical transition analysis for urban sustainability. The Struggle over Land in Africa: Conflicts, Politics and Change. South Africa: HSRC Press. http://hsrcpress. ac. za.

29. Magigi, W. (2013). Community Involvement in Informal Settlements Upgrading: Evidence from Dar Es Salaam Metropolitan City, Tanzania. Journal of Research on Humanities and Social Sciences, 3(12), 75-89

30. Meyer, W. B. (2000). The other Burgess model. Urban Geography, 21(3), 261-270.

31. Mkalawa, C. C., \& Haixiao, P. (2014). Dar es Salaam city temporal growth and its influence on transportation. Urban, Planning and Transport Research, 2(1), 423-446.

32. Montgomery, M. (2007). United Nations Population Fund: State of World Population 2007: Unleashing the Potential of Urban Growth. Population and Development Review, 33(3), 639-641.

33. Opoko, A. P., \& Oluwatayo, A. (2014). Trends in Urbanisation: Implication for Planning and Low-Income Housing Delivery in Lagos, Nigeria. Architecture Research, 4(1A), 15-26.

34. Oyeleye, O. I. (2013). Challenges of urbanization and urban growth in Nigeria. American Journal of Sustainable Cities and Society, 2(1), 79-95.

35. Pissourios, I. (2014). Top-down and bottom-up urban and regional planning: towards a framework for the use of planning standards. European spatial research and policy, (21/1), 83-99. 
36. Robinson Jr, J. W., \& Green, G. P. (2011). Introduction to community development: Theory, practice, and service-learning. Sage Publications, India.

37. Roy, U., \& Ganguly, M. (2009). Integration of Top down \& Bottom up approach in Urban and Regional Planning: West Bengal Experience of Draft Development Plans (DDP) and beyond National Town \& Country Planners Congress. Goa: India.

38. Saad-Sulonen, J. C., \& Horelli, L. (2010). The value of Community Informatics to participatory urban planning and design: a case-study in Helsinki. The Journal of Community Informatics, 6(2).

39. Shaibu, T. (2010). The Relationship between Urbanization and Economic Development in Developing Countries. International Journal of Economic Development Research and Investment, 1 (2): 30-36.

40. Steiniger, S., Poorazizi, M. E., \& Hunter, A. J. (2016). Planning with Citizens: Implementation of an e-Planning Platform and Analysis of Research Needs. Urban Planning, 1(2).

41. Tumbe, C. (2016). Urbanization, Demographic Transition and the Growth of Cities in India, 1870-2020. International Growth Centre Working Paper C-35205INC-1.

42. URT (2012). Formalisation of Informal Urban Settlements in Tanzania. Dar es Salaam: Property and Business Formalisation Programme: Dar es Salaam. 1

43. URT (2012). Property and Business Formalization Program Experience in Formalization of Squatter Settlements; Engaging Citizens in the Process, UNPSA Forum. June 2012. New York.

44. Vincent, C., \& Stephen, C. (2015). Local Government Capacity Building and Development: Lessons, Challenges and Opportunities. Journal of Political Sciences \& Public Affairs, 1-5.

45. Wallin, S., \& Horelli, L. (2012). Playing with the glocal through participatory eplanning. The Journal of Community Informatics, 8(3).
46. Yonder, A., Araujo, K. and Chaves, P. (2011). Land Regularization with Gender Equality; Ponte do Maduro in Recife, Brazil. Un Habitat.

47. Zhang, Y. (2015). Public Participation Approaches for Urban Planning in China. University of Wisconsin-Madison, United States. 